\title{
Malignant melanoma of the penis and urethra: one case report
}

Yunxiang $\mathrm{Li}^{1,2 \dagger}$, Haichao Yuan ${ }^{1 \dagger}$, Anguo Wang ${ }^{2}$, Zongping Zhang ${ }^{2}$, Ji Wu² and Qiang Wei ${ }^{{ }^{*}}$

\begin{abstract}
We present a case of a patient with malignant melanoma of the glans penis and urethra, which was found in a 53-year-old man with nonhealing ulcerative penile lesion and bilateral, clinically palpable inguinal lymphadenopathies at diagnosis. A diagnostic biopsy showed the characteristics of a melanoma. We treated the patient with total penectomy and bilateral inguinal lymph node dissection. After surgery, chemotherapy with bleomycin, vincristine and cisplatin and immunotherapy with thymosin injection were started. No recurrence or metastasis occurred during the 3 years after the operation. Melanoma of the penis is very rare, and early diagnosis is important because the patient prognosis is very poor.
\end{abstract}

Keywords: Melanoma, Penis, Urethra

\section{Background}

Malignant melanoma of the penis is an extremely rare malignancy that accounts for less than $2 \%$ of all primary penile malignant lesions [1]. They are located on the glans penis (55\%), prepuce (28\%), penile shaft (9\%) and urethral meatus (8\%) [2]. Malignant melanoma of the penis and urethra as comorbid presentations are more rare. We present a case of a patient with multifocal melanoma of both the glans penis and urethra, which, to the best of our knowledge, has not been previously described. We also provide a review of the literature, with emphasis on the pathogenesis and treatment of melanoma of the penis and urethra.

\section{Case presentation}

A 53-year-old man presented to our institution in 2009 with a 24-month history of difficulty in urinating and a 6-year history of melanin pigmentation of the glans penis. He did not have a family history of malignant melanoma. He had experienced urethral orifice suffusion after sex during the preceding 4 months. His physical examination revealed patchy erythema melanin pigmentation that was scattered in the glans penis and coronary sulcus and involved the urethral meatus (Figure 1A).

\footnotetext{
*Correspondence: weiqiang765@126.com

${ }^{\dagger}$ Equal contributors

${ }^{1}$ Department of Urology, West China Hospital, Sichuan University, Guoxue Xiang \#37, Chengdu, Sichuan, P.R. China

Full list of author information is available at the end of the article
}

The melanin-like lesions were discovered in the urethra through urinary cystoscopy. We performed a punch biopsy in two different sites: the glans penis and urethra. His histopathological examination revealed a malignant melanoma. Computed tomographic scans of the head, chest and abdomen were negative for metastatic disease. There was no palpable inguinal lymphadenopathy. Total penectomy and bilateral inguinal lymph node dissection were performed. The penis was cut open longitudinally, and we found $8-\mathrm{cm}$ melanin pigmentation in the pendulous urethra (Figure 1B). Pathological sections showed that the malignant melanoma invaded into superficial muscular layer. Histologic examination of these specimens revealed positive staining with hematoxylin (Figure 2A), HMB-45 (Figure 2B) and CD68 (Figure 2C). Bilateral inguinal lymph node specimens were negative. After surgery, the patient was started on an 8-week course of chemotherapy with bleomycin, vincristine and cisplatin and immunotherapy with thymosin injection. The patient had no tumor recurrence at the 2-year follow-up and remains alive to date.

\section{Discussion}

Melanoma of the penis is rare [3]. It is a disease of the elderly, with a peak incidence in the 50- to 70-year-old age group. The peak incidence of cutaneous melanomas in other areas of the body occurs in patients 40 to 49 years of age $[1,4]$. Because melanoma can metastasize 


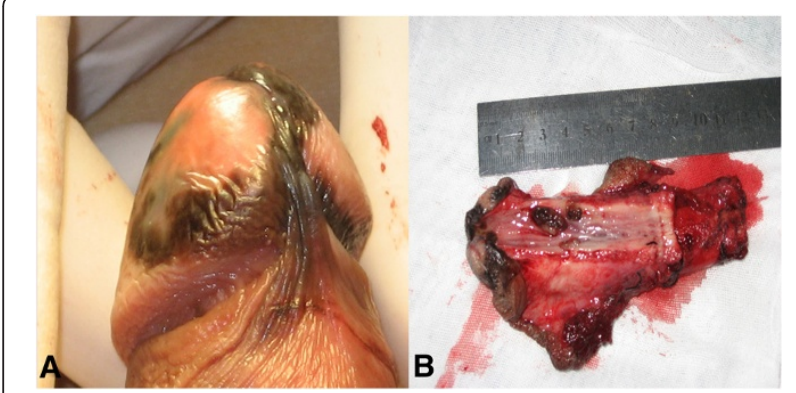

Figure 1 Multifocal melanoma of both the glans penis and urethra. (A) Uniform dark brown pigmented macule partially occupying the glans penis, coronary sulcus and urethral meatus. (B) Longitudinal incision of the penis showed 8-cm melanin pigmentation in the pendulous urethra.

to any tissue or organ early, it is one of the most dangerous tumors. The 2- and 5-year overall survival rates are $63 \%$ and $31 \%$, respectively [4]. In several studies, researchers have reported melanoma of both the penis and the urethra. However, melanoma of the urethra is less rare than that of the penis. Involvement of the urethra occurs most frequently in the fossa navicularis. It occurs less often in the pendulous, bulbous and prostatic areas [5]. In our patient, melanomas were found in the penis and urethra at the same time.

Prediction of the clinical course of melanoma is based mainly on tumor thickness. However, the assessment of tumor thickness alone is not enough; other important factors in the prognosis are the tumor's extent of involvement of local structures and whether there is clinical or histopathological evidence of metastases in the inguinal or pelvic lymph nodes [4]. Adverse prognostic factors are thickness $(\geq 3.5 \mathrm{~mm})$, ulceration and diameter ( $\geq 15 \mathrm{~mm}$ ) [6].

Early diagnosis is of importance because the risk of distant metastases is high [7]. Melanoma is potentially curable if the pathological characteristics are favorable
[8], but penile melanomas are usually diagnosed late. Clinically, they may vary in presentation from macules to papules and nodules, all of varying color. The absence of symptoms, the low level of public awareness and the difficulty associated with treatments at this site, as well as-not least in importance-embarrassment at being examined, all contribute to the delay in diagnosis [6]. Therefore, clinicians should be highly suspicious when examining any penile pathology. In clinical practice, we found that it was very difficult to recognize a pigmented penile lesion as a melanoma. Some authors have reported that dermoscopy is helpful for distinguishing a melanocytic lesion from a nonmelanocytic one and can play a role in establishing whether a melanocytic lesion is benign or malignant, which will improve the diagnosis $[6,9]$.

Staging of the disease, the choice of treatment and the patient's prognosis have traditionally been based on a system developed by Bracken et al., with stage I disease confined to the penis, stage II being metastatic to the regional lymph nodes and stage III representing disseminated disease [10]. Treatment of melanoma of the glans penis and urethra is surgical, but the main area of controversy lies with the extent of surgery for localized disease. Some authors $[10,11]$ believe in an aggressive surgical approach with total amputation of the penis and bilateral ilioinguinal node dissection. Recently, however, most authors $[12,13]$ have recommended wide local excision or distal amputation without lymph node dissection for lesions. Their rationale is that radical surgery may be overtreatment because it carries no survival advantage for stage II or III patients.

The prognosis for patients with melanoma is poor because of the lack of effective systemic chemotherapy. Combination chemotherapy consisting of six cycles of dacarbazine, carmustine, cisplatin and tamoxifen gives the best results. An overall response rate of about $45 \%$ and a complete response rate of $12 \%$ to $14 \%$ have been

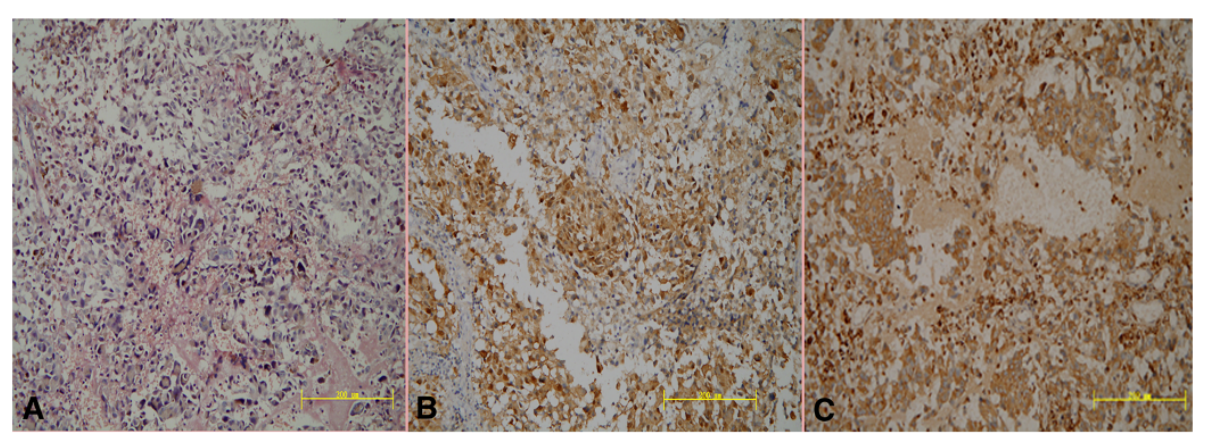

Figure 2 Histologic specimens. (A) Numerous atypical melanocytic cells with large hyperchromatic nuclei and abundant cytoplasm. The melanocytes were arranged in nests (hematoxylin and eosin stain; original magnification, $\times 200$ ). (B) Sections of the main tumor mass show strong positive staining for HMB-45 (original magnification, $\times 200$ ). (C) Sections of the main tumor mass show strong positive staining for CD68. The melanocytes were arranged in nests (original magnification, $\times 200$ ). 
reported. It is thought that $5 \%$ of patients with stage III melanoma can be cured $[14,15]$. In one study [16], researchers reported that treatment with high doses of adjuvant interferon in patients with high-risk stage II and stage III melanoma reduced the risk of disease recurrence and increased the median disease-free survival. In our patient, we started adjuvant therapy with thymosin and bleomycin, vincristine and cisplatin, without interferon. The prognosis for our patient is very good, and he remains alive to date.

\section{Conclusions}

We think that early detection was the key to effective treatment of our patient. In such patients, early recognition, early and appropriate aggressive surgical therapy and the development of effective adjuvant therapy are important elements of improving the prognosis.

\section{Consent}

Written informed consent was obtained from the patient for publication of this case report and any accompanying images. A copy of the written consent is available for review by the Editor-in-Chief of this journal.

\section{Competing interests}

The authors declare that they have no competing interests.

\section{Authors' contributions}

$Y X L$ and $H C Y$ were involved in drafting the manuscript. AGW and ZPZ were involved in acquisition of data and preparing the figures. QW and JW designed and revised the manuscript. All authors read and approved the final manuscript.

\section{Acknowledgements}

The study was financially supported by the Natural Science Foundation of China (81200551 and 81270841).

\section{Author details}

${ }^{1}$ Department of Urology, West China Hospital, Sichuan University, Guoxue Xiang \#37, Chengdu, Sichuan, P.R. China. ${ }^{2}$ Department of Urology, Nan Chong Central Hospital, Nanchong Renmin Nanlu \#97, Nanchong, Sichuan 610041, P.R. China.

Received: 28 March 2013 Accepted: 20 October 2014

Published: 11 November 2014

\section{References}

1. Stillwell TJ, Zincke H, Gaffey TA, Woods JE: Malignant melanoma of the penis. J Urol 1998, 140:72-75.

2. Tallerman A: Malignant melanoma of the penis. Urol Int 1972, 27:66-80

3. Demitsu T, Nagato H, Nishimaki K, Okada O, Kubota T, Yoneda K, Manabe M: Melanoma in situ of the penis. J Am Acad Dermatol 2000, 42:386-388.

4. van Geel AN, den Bakker MA, Kirkels W, Horenblas S, Kroon BB, de Wilt JH, Eggermont AM, Mooi WJ, van der Aa MN: Prognosis of primary mucosal penile melanoma: a series of 19 Dutch patients and 47 patients from the literature. Urology 2007, 70:143-147.

5. Pow-Sang JM, Klimberg IW, Hackett RL, Wajsman Z: Primary melanoma of the male urethra. J Urol 1988, 139:1304-1306.

6. De Giorgi V, Grazzini M, Massi D, Rossari S, Gori A, Janowska A, Bruscino N, Lotti T: Melanoma of the penis: a clinical dermoscopic case study. Acta Derm Venereol 2010, 90:87-88.

7. de Bree E, Sanidas E, Tzardi M, Gaki B, Tsiftsis D: Malignant melanoma of the penis. Eur J Surg Oncol 1997, 23:277-299.
8. Dogu GG, Yaren A, Tuncay L, Senturk N, Zumrutbas AE, Taskoylu BY, Bir F: Primary malignant melanoma of the penis: a case report. Med Oncol 2012, 29:1300-1303.

9. Mannone F, De Giorgi V, Cattaneo A, Massi D, De Magnis A, Carli P. Dermoscopic features of mucosal melanosis. Dermatol Surg 2004, 30:1118-1123.

10. Bracken RB, Diokno AC: Melanoma of the penis and urethra: 2 case reports and review of the literature. J Urol 1974, 111:198-200.

11. Manivel JC, Fraley EE: Malignant melanoma of the penis and male urethra: 4 case reports and literature review. J Urol 1988, 139:813-816.

12. Creagh TA, Murphy DM: Malignant melanoma of the penis. Aust N Z J Surg 1993, 63:820-821.

13. Fenn NJ, Johnson RC, Sharma AK, Attanoos RL, Horgan K: Malignant melanoma of the penis. Eur J Surg Oncol 1996, 22:548-549.

14. Mastrangelo MJ, Berd D, Bellet RE: Aggressive chemotherapy for melanoma. In Cancer: Principles \& Practice of Oncology, PPO Updates: Annual Advances in Oncology. Edited by De Vita VT Jr, Hellman S, Rosenberg SA. Philadelphia: Lippincott; 1991:1-11.

15. Reintgen D, Saba H: Chemotherapy for stage 4 melanoma: a three-year experience with cisplatin, DTIC, BCNU, and tamoxifen. Semin Surg Oncol 1993, 9:251-255.

16. Kirkwood JM, Ibrahim JG, Sondak VK, Richards J, Flaherty LE, Ernstoff MS, Smith TJ, Rao U, Steele M, Blum RH: High-and low-dose interferon alfa-2b in high-risk melanoma: first analysis of inter-group trial E1690/S9111/ C9190. J Clin Oncol 2000, 18:2444-2450

doi:10.1186/1477-7819-12-340

Cite this article as: Li et al:: Malignant melanoma of the penis and urethra: one case report. World Journal of Surgical Oncology 2014 12:340.

\section{Submit your next manuscript to BioMed Central and take full advantage of:}

- Convenient online submission

- Thorough peer review

- No space constraints or color figure charges

- Immediate publication on acceptance

- Inclusion in PubMed, CAS, Scopus and Google Scholar

- Research which is freely available for redistribution 